\title{
Higher Mean Platelet Volumes May Not Be Related with Survival in Cirrhotic Patients with Unresectable Hepatocellular Carcinoma
}

\author{
Cengiz Beyan $^{\mathrm{a}}$ Esin Beyan ${ }^{\mathrm{b}}$ \\ aDepartment of Hematology, Ufuk University Faculty of Medicine, Ankara, Turkey; \\ ${ }^{b}$ Department of Internal Medicine, Kecioren Training and Research Hospital, University of \\ Health Sciences, Ankara, Turkey
}

Dear Editor,

We read with a great interest the article of Scheiner et al. [1] about the association of platelet count and mean platelet volume (MPV) with the overall survival in patients with cirrhosis and unresectable hepatocellular carcinoma (HCC). They reported that thrombocytopenia and a higher MPV were associated with better outcomes in patients with advanced HCC. We would like to comment on the MPV results of their study.

First, the data in the study covered a very long time interval (1995-2016), and in the Materials and Methods section, the authors specified that the Sysmex XE-2100 hematology analyzer was used for MPV measurements. However, this instrument has only been used since 1999 for complete blood counting, and therefore, some data must have been obtained with different hematology analyzers. This is an important issue because it was shown that the various techniques of the different instruments for measuring the complete blood count lead to variations up to $40 \%$ in MPV results [2]. More importantly, the measurement times after venipuncture were not standardized due to the retrospective design of the study. After exposure to ethylenediaminetetraacetic acid, the MPV increases progressively up to $30-45 \%$ within the first $2 \mathrm{~h}$ after venipuncture usage with impedance method in complete blood count [3]. The MPV measurements by the MPV measurement times varied up to $12.5 \%$ in a meta-analysis study including the 1,181 studies about MPV indexed in the PubMed database since 2012, and this difference was notified as $2-50 \%$ in the review by Jackson and Carter [2, 3]. Additionally, Noris et al. [4] concluded that MPV has presently no role in making a diagnosis and defining the prognosis in any acquired illness due to the number of physiological variables such as platelet count, sex, age, and ethnicity affecting platelet size and the poor standardization of MPV measurement.

Second, the authors suggested that MPV was associated with platelet aggregation. This is not correct. The correlation between platelet parameters including MPV and the platelet aggregation results obtained with turbidimetric platelet aggregometry was not shown in various studies [5].

Furthermore, there was a statistical difference between the derivation cohort and validation cohort groups according to gender comparison $\left(\chi^{2}\right.$ statistic; $\left.p=0.006\right)$. This must not be ignored because the MPV values may exhibit variations according to age and sex [4].

As a result, a higher MPV may not be related with survival in cirrhotic patients with unresectable HCC.

Prof. Cengiz Beyan, MD

Department of Hematology, Ufuk University Faculty of Medicine

Boulevard of Mevlana (Konya Road) No. 86-88

Çankaya, 06830 Ankara (Turkey)

E-Mail cengizbeyan @ hotmail.com 
Beyan and Beyan: Higher Mean Platelet Volumes May Not Be Related with Survival in Cirrhotic Patients with Unresectable Hepatocellular Carcinoma

\section{Disclosure Statement}

The authors declare that they have no conflicts of interest to disclose.

\section{References}

1 Scheiner B, Kirstein M, Popp S, Hucke F, Bota S, Rohr-Udilova N, Reiberger T, Müller C, Trauner M, PeckRadosavljevic M, Vogel A, Sieghart W, Pinter M: Association of platelet count and mean platelet volume with overall survival in patients with cirrhosis and unresectable hepatocellular carcinoma. Liver Cancer, DOI: 10.1159/000489833.

2 Beyan C, Beyan E: Were the measurements standardized sufficiently in published studies about mean platelet volume? Blood Coagul Fibrinolysis 2017;28:234-236.

3 Jackson SR, Carter JM: Platelet volume: laboratory measurement and clinical application. Blood Rev 1993;7: 104-113.

4 Noris P, Melazzini F, Balduini CL: New roles for mean platelet volume measurement in the clinical practice? Platelets 2016;27:607-612.

5 Beyan C, Kaptan K, Ifran A: Platelet count, mean platelet volume, platelet distribution width, and plateletcrit do not correlate with optical platelet aggregation responses in healthy volunteers. J Thromb Thrombolysis 2006;22:161-164. 